\title{
Tourists' motives, expectation and experience to historical sites in Hunan province
}

$\mathrm{Li}, \mathrm{Ce}$

Huaihua University, China (974681434@qq.com)

Borbon, Noelah Mae D. $\$

Lyceum of the Philippines University Batangas, Philippines (nmdborbon@lpubatangas.edu.ph)

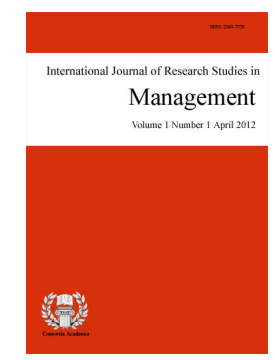

ISSN: $2243-7770$ Online ISSN: 2243-7789

OPEN ACCESS

\section{Abstract}

Heritage tourism is considered as a rapidly growing sector of tourism making up a very important component of tourism for many regions. In recent years, Hunan has attached great importance to the development of tourism. The area is a region inhabited by ethnic minorities and rich in ecological resources, and is also a famous tourist destination in China. It is quite important to understand tourists' motives, expectation and experience that influence the performance of the historical sites, and for a better management of the site in accordance with the desires and expectations of visitors. This study aims to assess the Tourists' Motives, Expectation and Experience to Historical Sites in Hunan Province. The researcher in this study used the descriptive survey research method. The finding reveals that There was a significant relationship exists and implies that the better the experience, the higher the level of motives, the higher the expectation and the higher the level of experience. It was recommended for the Chinese Government may consider restructuring the historical sites making it to have modern and visual appeal on built environment without losing its value and to boost Enjoyment in Historical sites, there can be recreational activities facilitated by the tour guides.

Keywords: motives, expectations, experience, heritage tourism, Hunan Province 


\section{Tourists' motives, expectation and experience to historical sites in Hunan province}

\section{Introduction}

Heritage tourism is considered as a rapidly growing sector of tourism making up a very important component of tourism for many regions. Some researchers define heritage tourism simple as people visiting heritage places or viewing historical sites. Heritage tourism is based on visits by people who want to learn something new or enhance their lives in some ways (Timothy, 2011). Hall et al. (1998) have pointed that it is the human dimension that gives rise to heritage resources. The continued rapid growth of tourism has made it one of the most important industries in the world. WTTC's latest annual research shows the Travel \& Tourism sector experienced $3.5 \%$ global growth in 2019, outpacing that of the global economy $(2.5 \%)$ for the ninth consecutive year. It also accounted for $10.3 \%$ of global GDP in 2019 with created 330 million jobs while one in four new jobs were created by the sector, it has been making $\$ 948$ billion capital investment in 2019 (4.3\% of total investment). Moreover, WTTC's latest research also shows that the Chinese Tourism sector has contributed of $11.3 \%$ to total economy, with a growth of $9.3 \%$ in 2019 Tourism GDP vs $6.1 \%$ real economy GDP growth. It created 79,870 jobs which accounted for $10.3 \%$ of total employment.

Travel motivation is an important psychological factor that motivates tourists to make travel decisions and implement travel behaviors. Travel motivation is often described as an individual's willingness and internal demand for tourism behavior (Sekiguchi et al., 2019). It has an important influence on tourism decision-making and its experience, perception, and behavior. In an academic context, there is a need to enhance our understanding of the motivations of tourists. In other view, tourists believe that the products or services provided by the destination should achieve a certain performance. When this expectation is reached, the tourists will be satisfied, otherwise they will be dissatisfied. In the marketing context, expectation is the perception prior to experiencing a product or preconceived attributes. Expectations can be considered a comparative judgment in which satisfaction increases as the performance/expectation ratio increases ( $\mathrm{Li}$ et al., 2011). Meanwhile, the experience of tourists affects tourists' perception of tourist destinations, thereby affecting the tourist attraction of tourist destinations (Chen \& Chen, 2020).

Hunan is a provincial administrative region in China with a total area of 21,800 square kilometers. At the end of 2019, the province has a permanent population of $69,183,800$. Its provincial capital is in Changsha. The area is a region inhabited by ethnic minorities and rich in ecological resources and is also a famous tourist destination in China. In recent years, Hunan has attached great importance to the development of tourism. In 2019, Hunan Province received 828 million domestic and foreign tourists and achieved a total tourism revenue of 944.2 billion yuan, an increase of $10 \%$ and 13\% respectively year-on-year. Hunan has a wealth of historical tourist attractions. Among them, Yan Emperor Mausoleum, Shun Emperor Mausoleum, Lieye Ancient City Ruins, Mao Zedong's Former Residence, Wuxi Cliff Rock Carvings, Yuelu Academy, Nanyue Hengshan Mountain, Phoenix Ancient City, Chinese People's Anti-Japanese War Victory Memorial Hall and Yueyang Tower are among the top ten historical sites in Hunan Province.

Understanding tourist motives is critical but knowing the predictors of successful tourist destination encounters is also useful for destination planning and management. It was suggested that when developing various travel products and promotional programs, marketing should consider tourist variability and demographic-based needs (Mutanga et al., 2017) It is quite important to understand tourists' motives, expectation and experience that influence the performance of the historical sites, and for a better management of the site in accordance with the desires and expectations of visitors. Heritage tourism should be developed based on the relationship between individuals and the heritage presented and, more specifically, based on the understanding of tourist motivations and behavior for further management of the site. 
At present, world tourism is gradually showing the development trend of leisure, popularization, and socialization. As a way of returning to nature and returning to history, historical heritage tourism is favored by more and more tourists. Whether the development of historical heritage tourism is successful, the key lies in the satisfaction of tourists with their tourism experience. Tourist satisfaction is the result of comparing the expectations of the destination with the experience of the tourists when they visit the place. As the starting point of tourism activities, tourism motivation is the direct cause of tourists' travel destination selection, travel consumption and other travel behaviors. Each tourist destination should pay attention to tourists' travel motives and travel expectations, to improve the satisfaction of tourists' experience. Hunan has many high-quality historical sites, but currently, there are few studies on Hunan's historical sites tourism. This research can enrich the research results of Chinese historical heritage tourism and motivation-expectation-experience. At the same time, it provides strong support for the marketing promotion, service improvement, facility improvement, and environmental optimization of Hunan's historical relics.

\subsection{Objectives of the Study}

This study aims to assess the Tourists' Motives, Expectation and Experience to Historical Sites in Hunan Province. More specifically, it aims to answer the following: to present the demographic profile of the respondents in terms of age, sex, employment status, frequency of visit, type of tourist and travel party; to determine the tourists' motives in visiting the historical sites in terms of travel motivation, attribute evaluation and emotional involvement; assess tourists' expectation to historical sites in terms of environment, range of attraction, tourism services and transportation; determine the levels of experience in historical sites in terms of learning experience, emotional experience, meaningful experience and enjoyment; to determine the significant differences among the responses when grouped according to profile; to determine the relationship among the variables; and to proposed a framework based on the result of the study.

\section{Methods}

Research design - The researcher in this study used the descriptive survey research method. With the use of descriptive method, the researcher needs to be observant into a larger crowd and there is a necessity to include variables to the conclusion. The researcher by using descriptive research can effectively design a pre-structured questionnaire with closed ended questions. In this study, researcher obtained first-hand data of tourists' motives, expectation, and experience, including basic characteristics of tourists, via questionnaire surveys of tourists in related scenic historical sites in Hunan.

Participants - The respondents of the study are the tourists from historical sites in Hunan. Due to the impact of the COVID-19 epidemic on tourism, tourists in these historical sites maybe scarce or even zero, therefore, this survey is mainly based on online survey and supplemented by on-site survey. The researcher will provide online questionnaire links to tourists who visited these historical sites through travel agencies to collect data. There are a total of twenty-eight (28) historical sites above national 4A-level in Hunan, which composed of twenty (20) 4A-level tourist attractions and eight (8) 5A-level tourist attractions. Upon the data gathering, a total of three hundred ninety-seven (397) respondents will be collected.

Data gathering instrument - In order to accurately determine the relationship among tourists' motives, expectation and experience in historical sites of Hunan, the researcher designed the questionnaire on the basis of reference to relevant papers, reports, and consultation with some experts and scholars. The questionnaire consists of four parts. The first part is the demographic profile of the respondents. The researcher formulated a questionnaire which includes the following information: gender, age, employment status, frequency of visit, type of tourists and travel party. The second part was a questionnaire which was used to get the quantitative result for the motives of tourists in visiting the historical sites in Hunan. The third part was a questionnaire which was used to get the quantitative result for the expectation to the historical sites in Hunan. The fourth part was a questionnaire about the level of the experience in historical sites in Hunan. 
Data gathering procedures - With the use of the WeChat group and the online questionnaire survey platform, the researcher was able to send the questionnaires and conduct the survey. The researcher also goes to some historical sites to set an interview for those tourists who is willing to be interviewed and had a focused discussion with them. The researcher proceeded to the actual place to administer the instrument for the distribution and retrieval, tallied the gathered data, interpreted, and analyzed, conceptualized the conclusion and recommendation based on the results of the study. The collected data were kept with utmost confidentiality and were used for academic purposes only.

Data analysis - After the retrieval of the questionnaire, data were allied and interpreted using different statistical tools such as frequency distribution and weighted mean. The above-mentioned tools were used based on the objectives of the study. Frequency distribution identified the number of responses in each statement aid in the questionnaire. Weighted mean was used to answer the feedback of respondents in visiting historical sites in Hunan Province based on their expectations and experiences. Whereas Analysis of Variance (ANOVA) determined the significant relationship between the relationship among Tourists' Motives, Expectation and Experience in visiting the historical sites when grouped according to the profile variables. All data were presented using the SPSS software. Moreover, the researcher utilized the SPSS to determine the relationship among Tourists' Motives, Expectation and Experience, so as to propose more targeted policy recommendations to improve the level of tourism development in this region.

\section{Results and discussion}

Table 1

Percentage distribution of the respondents' profile

\begin{tabular}{lcc}
\hline \multicolumn{1}{c}{ Age } & Frequency & Percentage (\%) \\
\hline 18-26 years old & 151 & 38.00 \\
27-35 years old & 115 & 29.00 \\
36-44 years old & 75 & 18.90 \\
45 years old and above & 56 & 14.10 \\
\multicolumn{1}{c}{ Sex } & & \\
Male & 114 & 28.70 \\
Female Occupation & 283 & 71.30 \\
Employed & & \\
Unemployed & 250 & 63.00 \\
Student & 19 & 4.80 \\
Others & 87 & 21.90 \\
Frequency of Visit & 41 & 10.30 \\
Once & & \\
Twice & 173 & 43.60 \\
Thrice & 126 & 31.70 \\
More than thrice & 19 & 4.80 \\
Local Tourist & 79 & 19.90 \\
Tourists from other provinces & & \\
Travel Party & 339 & 85.40 \\
Alone & 58 & 14.60 \\
Family & & \\
Organized Group & 25 & 6.30 \\
Friends & 181 & 39.30 \\
\hline
\end{tabular}

Table 1 presents the percentage distribution of the respondents. Most of the respondents 18-26 years old with 151 or 38 percent, followed by those aged 27-35 years old with 115 or 29 percent while the 75 or 18.9 percent are ages 36-44 years old, and the rest are 45 years old and above with 56 or 14.10 percent. The 114 respondents or 28.70 percent are male; the 283 or 71.30 percent are female. Majority of the respondents are

18 Consortia Academia Publishing (A Partner of Tourism Educators and Movers of the Philippines) 
employed with 250 or 63 percent and 87 or 21.90 percent are students. Majority of the respondents visit the place for once-a-year basis with 173 or 43.60 and most of them are classifies as local tourist which composed of 339 or 85.40 percent. They are mostly traveling with their family with 181 or 45.60 percent or with their friends 156 or 39.30 percent.

In China, with the deep integration of the cultural industry and the tourism industry, historical sites everywhere are introducing new technologies and methods to enhance the attractiveness of their tourism products and make historical sites more accessible to the young people. As a result, more and more young tourists putting historical sites in their tour plans, and the tourist groups of historical sites are showing a younger trend. On the other hand, many historical sites in China adopt the form of free-of-charge visits by appointment, which attracts many family-driven tourists, and more and more historical sites are becoming check-in locations for free-travel tourists. With the improvement of women's income and social status, the economic influence of Chinese women in the field of tourism consumption has increased rapidly. Most of the family travel consumption decisions are made by wives. These female travelers account for the largest proportion of professional and senior workers, followed by freelancers and retirees. Compared with male tourists, female tourists prefer to travel to historical sites. To capture the important tourist group of women, many historical sites and scenic spots have carried out a lot of targeted marketing and achieved good results.

\section{Table 2}

Tourists' motives in visiting the historical sites

\begin{tabular}{llccc}
\hline & \multicolumn{1}{c}{ Indicators } & Composite Mean & Verbal Interpretation & Rank \\
\hline 1. & Travel Motivation & 3.08 & Agree & 1 \\
2. & Attributes Evaluation & 3.07 & Agree & 2 \\
3. & Emotional Involvement & 3.06 & Agree & 3 \\
\multicolumn{2}{c}{ Composite Mean } & 3.07 & Agree & \\
\hline
\end{tabular}

Table 2 presents the Tourists' Motives in Visiting the Historical Sites. Travel Motivation Ranks first with the composite mean of 3.08 and emotional involvement ranked last with the composite mean of 3.06. Both indicators are verbally interpreted as agree.

Table shows motivation is an important factor affecting consumer choice. Travel motivation ranked highest mainly because if there is no tourist motivation, even if the tourist has enough time and money, he will not go out to travel. Because tourists don't know why they travel, they don't know where to travel, and they don't even know what to do when they reach their destination. Only when tourists think that tourism is a reasonable and valuable, meaningful, and worthy of consumption activities, he will invest these time and money into tourism activities. The generation of tourism motivation is largely governed by a person's cultural quality or education level. The more developed the culture, the stronger the desire of people to travel. When travelers' needs are stimulated, they form travel motivations, which drive these travelers to take actions to meet their tourism needs, motivations are hence of utmost criticality in traveler behavior (Hsu et al., 2017). Second, to increase competitiveness, historical sites management organizations and other actors of the tourism system should also pay particular attention to the tourist's attributes evaluation.

Least in the rank, emotional involvement (3.06). Emotional Involvement ranked lowest mainly because the emotional interaction between historical sites and tourists is not deep and comprehensive enough. The deep emotional resonance and dependence between scenic spots and tourists has not been established. The cultural characteristics and personalities contained in historical sites are inconsistent with the characteristics and values of tourists themselves. Therefore, tourists are less emotionally involved in the process of visiting historical sites. Emotions associated with the characteristics of tourist sites, whose perception by the subject generates an attraction force, more or less strong, according to his/her perception of the tourist destination. The ability to engender those positive emotional involvements at the destination is a source of competitive advantage for the marketer. 
Li, C., \& Borbon, N. M. D.

Table 3

Tourists' expectation to historical sites

\begin{tabular}{lccc}
\hline \multicolumn{1}{c}{ Indicators } & Composite Mean & Verbal Interpretation & Rank \\
\hline 1. Environment & 3.22 & Moderately Expected & 4 \\
2. Range of Attractions & 3.34 & Moderately Expected & 3 \\
3. Tourism Services & 3.44 & Moderately Expected & 2 \\
4. Transportation & 3.53 & Highly Expected & 1 \\
$\quad$ Composite Mean & 3.38 & Moderately Expected & \\
\hline
\end{tabular}

Table 3.5 presents the Summary Table on the Tourists' Expectation to Historical Sites. It was revealed that respondents have a moderately expectation with the composite mean of 3.38. Transportation ranks first with the composite mean of 3.53 verbally interpreted as highly expected. Tourism has expanded largely due to the improvement of transportation. As the tourist's journey to and from the destination is a fundamental component of the holiday. They have the highest expectations for tourism transportation. High-speed rail and highways have become the preferred form of transportation for Chinese tourists. Inconvenient transportation or poor accessibility of historical sites will undermine tourists' willingness to visit. There is a close connection between the improvement of the transportation and the development of the tourism industry. Tourist destinations should fully analyze the impact of travel time cost and expense cost on scenic spots to subdivide the tourist market of different income levels (Yin, 2012). Meanwhile, environment ranked last with the composite mean of 3.22 verbally interpreted as moderately expected. China has classified various historical sites. Different levels of historical sites have different requirements for the environmental indicators. Tourists can estimate various environmental indicators based on the level of the scenic spots they visit. The high-quality scenic environment can enable tourists to get a good experience during the tour, thereby improving the perception of environmental restoration. The management of the scenic spot should pay attention to the environmental quality of the tourist area and do a good job of management (Zhang, 2021).

\section{Table 4}

Level of experience in historical sites

\begin{tabular}{llccc}
\hline \multicolumn{1}{c}{ Indicators } & WM & Verbal Interpretation & Rank \\
\hline 1. & Learning Experience & 3.25 & Moderately Experienced & 1 \\
2. Emotional Experience & 3.15 & Moderately Experienced & 3 \\
3. Meaningful Experience & 3.19 & Moderately Experienced & 2 \\
4. Enjoyment & 3.12 & Moderately Experienced & 4 \\
\multicolumn{2}{r}{ Composite Mean } & 3.18 & Moderately Experienced \\
\hline
\end{tabular}

Table 4 presents the Summary Table on the level of experience in Historical Sites. Learning experience ranks first with the composite mean of 3.25 verbally interpreted as moderately experience. This may have ranked highest basically because operators of historical sites attach great importance to the systematic arrangement and presentation of historical knowledge. Tourists can learn a wealth of historical and cultural knowledge during the visit. Meanwhile enjoyment ranked last with the composite mean of 3.12 verbally interpreted as moderately experienced. This may rank least basically because comprehensive management, tour services and product experience have affected the satisfaction of tourists. Most historical sites lack management funds and professional staffs, resulting in insufficient number of experiential tourism products and low-quality tourism services, which affects the enjoyment of tourists.

Historical sites are the keeper and recorder of history, and they are responsible for protecting and inheriting human civilization. In China, the educational function of historical sites has become increasingly important. Visiting historical sites is essentially historical consumption, knowledge consumption, and cultural consumption. This consumption helps people increase their knowledge, help people understand relevant folklore, humanities, geography, history, etc. more systematically and professionally. Compared with shopping, Chinese are now showing greater interest in cultural tourism experience, and more and more young tourists have become the main tourists of historical sites. Hence historical sites should combine educational technologies and the educational 
Tourists' motives, expectation and experience to historical sites in Hunan province

content to take full advantage of their values and enhance the visitor experience (Hertzman et al., 2008).

\section{Table 5}

Relationship between tourists' motives, tourists' expectation and level of experience in historical sites

\begin{tabular}{lccc}
\hline \multicolumn{1}{c}{ Tourists' Expectation } & F-value & p-value & Interpretation \\
\hline Environment & $0.723^{* *}$ & 0.000 & Highly Significant \\
Range of Attractions & $0.650^{* *}$ & 0.000 & Highly Significant \\
Tourism Services & $0.568^{* *}$ & 0.000 & Highly Significant \\
Transportation & $0.491^{* *}$ & 0.000 & Highly Significant \\
\hline \multicolumn{1}{c}{ Level of Experience in Historical Sites } & & & \\
\hline Learning Experience & $0.673^{* *}$ & 0.000 & Highly Significant \\
Emotional Experience & $0.723^{* *}$ & 0.000 & Highly Significant \\
Meaningful Experience & $0.723^{* *}$ & 0.000 & Highly Significant \\
Enjoyment & $0.708^{* *}$ & 0.000 & Highly Significant \\
\hline
\end{tabular}

Table 5 presents the correlation between the tourists' motives in visiting the historical sites, tourist expectation and level of experience in historical sites. It was observed that there was a strong direct correlation between the tourists' motives in visiting the historical sites, tourist expectation; tourists' motives in visiting the historical sites and level of experience in historical sites. In addition, the resulted p-values were less than 0.01 alpha level, thus the null hypothesis is rejected. This means that there was a significant relationship exists and implies that the better the practices, the higher the level of motives, the higher the expectation and the higher the level of experience. The stronger the tourist motives of learning, social interaction, and cultural experience, the higher the expectations of historical sites. They will pay more attention to related knowledge and events during the tour, and therefore, their sense of gain will be higher. The better the experience. The perceived value of tourists has a complete mediating effect on tourism motivation and satisfaction. Therefore, historical sites can increase the satisfaction of tourists by improving the perceived value of tourists.

\section{Table 6}

Relationship between tourists' expectation and level of experience in historical sites

\begin{tabular}{lccc}
\hline & r-value & $p$-value & Interpretation \\
\hline Learning Experience & $0.715^{* *}$ & 0.000 & Highly Significant \\
Emotional Experience & $0.651^{* *}$ & 0.000 & Highly Significant \\
Meaningful Experience & $0.679^{* *}$ & 0.000 & Highly Significant \\
Enjoyment & $0.669^{* *}$ & 0.000 & Highly Significant \\
\hline
\end{tabular}

Table 6 shows the relationship between tourists' expectation and level of experience in historical sites. As seen from the table, the resulted $r$-values indicates a strong direct correlation, and the computed $p$-values were less than 0.01 alpha level. Thus, as significant relationship exists and the result indicates that the higher the expectation, the higher the level of experience on historical sites. This could be explained to the fact that as the tourist have higher expectation towards the destination the more the tourist explores and have open their minds to the possibility to have good experience in the destination.

When tourists have high expectations for historical sites, they will put more energy into the process of visiting, and then get a better experience and greater satisfaction. Therefore, it is necessary to use a variety of methods for marketing of historical sites to stimulate tourists' curiosity and desire to explore, so that tourists can visit with high expectations and return with satisfaction.

Tourist destinations with rich historical relics and high-quality tourist services are very attractive to tourists. Visitor satisfaction often plays an important role in tourists' post visit behavior and visitors' intentions; therefore, it is crucial to create a meaningful, memorable and satisfying experience as this may result in increased visitors' loyalty and gaining a competitive advantage, it is paramount importance to the management and development. 


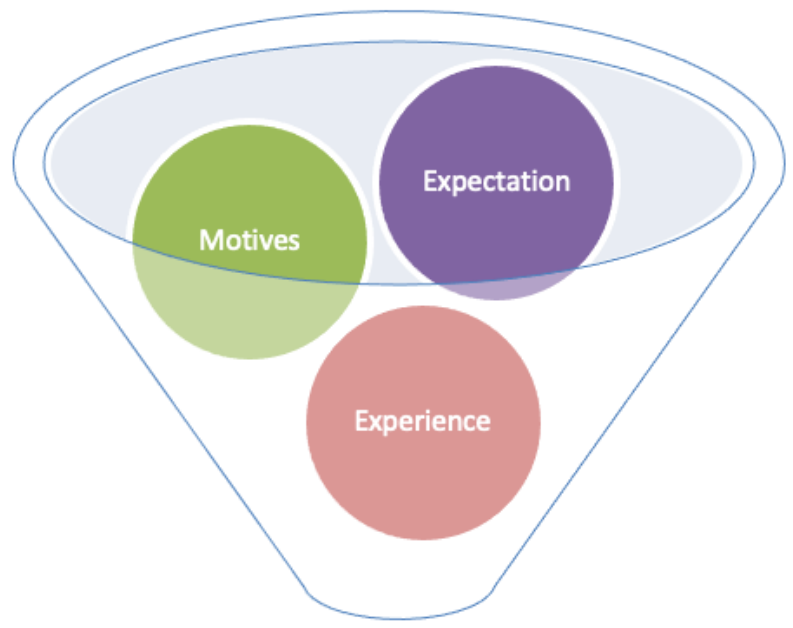

Figure 1. Historical Site Framework

Given the result of the test of relationship, which reveals that there was a significant relationship exists and implies that the better the experience, the higher the level of motives, the higher the expectation and the higher the level of experience. As seen in the figure, the proposed framework is in the form of an inverted cone. The inverted cone is intended to represent a dynamic mechanism, such as movement. From the perspective of time, memories travel through the cone, influencing thought and behavior. Also, it depicts the level of each variable which means that the better the experience, the higher the level of motives, the higher the expectation and the higher the level of experience.

It can also be observed that Experience is in red color as it depicts excitement, cheerfulness, stimulation, and aggression, while motive is in green color as it represents security, calm, and peace and lastly, Expectation is in violet since it is associated with mood, beliefs, and perception. Tourist Motive's towards Historical site is correlated to tourist's experience as well as expectation. In any circumstance, the tourist's experience begins with a motivation and urge to travel. Thus, its motivation will also influence their expectation towards the destination and eventually will affect in the overall tourist's expectation. Relatively, Tourist Experience towards Historical site is correlated to tourist's Motives as well as expectation. Experience of the tourist is manipulated by their expectation whether the expectation was met or exceed, or worse not met. Whereas the motivation to travel will urge the tourist to fully experience the tourist destination.

On the other hand, Tourist Expectation towards Historical site is correlated to tourist's experience as well as Motives. Expectation of the tourist is a factor for tourist to be motivated to go to a certain destination and will effect on the overall travel experience of the tourist. The higher the proportion of return visits, the better the tourists' experience and contentment. When compared to first-time tourists, repeat tourists behave differently in the location. Naturally, the level of novelty is lesser than for first-time guests. To boost the level of uniqueness, destination marketers and managers should collaborate in tourism strategy and market initiatives.

Tourists' motives have higher expectations for the identification system and information services as a result. The presence of tourist attraction signs is important for promoting historical site aspects, demonstrating cultivated values, providing barrier-free tourism, and promoting the development of the tourist attraction. It also has intangible cultural heritages to be inherited, and many traditional customs are relatively completely preserved in ancient villages and towns. But what is easily neglected in the protection and development of ancient villages is the importance of cooperative governance among the main bodies of interest. Therefore, in the context of cooperative governance, the protection and development of historical and cultural villages is explored, with the hope to provide the reference for the further development of famous historical and cultural village ( $\mathrm{Lu}$, 2017). 
Famous historical and cultural village is the important real carrier of traditional Chinese clan culture. It has many materials cultural heritages that cannot be copied, and its architectural style, characteristic and layout vividly embody the clan concept and cultural view of traditional cluster villages in China. Rather than returning to a previously visited tourist spot, most people choose to travel to a new location to immerse themselves in the next unique history, cuisine, or architecture. The unknown has always piqued my interest. Tourists will substantially expand their knowledge and perceive the world from a new viewpoint if they incorporate experience, learning, and emotional resonance into their vacation. With the growth of tourism and the rising need for culture, historical sites have emerged as a new hotspot for Chinese visitors. Historical sites are repositories for historical imprints and regional culture, as well as spiritual civilization's legacy.

\section{Conclusion and recommendation}

Majority of the respondents are aged 18-26 years old, female, Employed, traveled once a year, classified as local tourist, and traveling with family. As to the Tourists' Motives in Visiting the Historical Sites, most of the respondents agreed in terms of travel motivation. With regards to the Tourists' Expectation in Visiting the Historical Sites, most of the respondents have high expectation on transportation. There was a significant relationship exists and implies that the better the experience, the higher the level of motives, the higher the expectation and the higher the level of experience. It was found out that 36 to 44 years old have higher motives in visiting historical sites. It was also found out that those who visit historical sites more than thrice have higher motives in terms of travel motivation, while those who visit thrice have higher motives in terms of attributes evaluation and higher level of experience as to enjoyment.

It is recommended that to involve the tourist emotionally, the historical site management may have personal notes and welcoming so that the tourist may feel special when visiting the site. The Chinese Government may consider restructuring the historical sites making it to have modern and visual appeal on built environment without losing its value. To boost Enjoyment in Historical sites, there can be recreational activities facilitated by the tour guides. Creative opportunities may be sought to encourage the co-creation of positive, unique, and quality tourist experiences that can attract visitors efficiently. Historical sites may combine educational technologies and the educational content to take full advantage of their values and enhance the visitor experience. Future researcher may conduct similar study on historical sites, analyzing the impact of COVID 19 to the tourism especially on the historical sites.

\section{References}

Chen, X., \& Chen, W. (2020). Why does a bar street become popular in ancient towns in China? From the perspective of tourists' embodied experience. Tourism Tribune, 35(9), 113-122.

Hall, C. M., \& McArthur, S. (1998). Integrated heritage management: Principles and practice. London: The Stationary Office.

Hertzman, E., Anderson, D., \& Rowley, S. (2008). Edutainment heritage tourist attractions: A portrait of visitors' experiences at Storyeum. Museum Management and Curatorship, 23(2), 155-175. https://doi.org/10.1080/09647770802012227

Hsu, C., Lee, W., \& Chen, W. (2017). How to catch their attention? Taiwanese flash packers inferring their travel motivation from personal development and travel experience. Asia Pac. J. Tour. Res., 22, 117-130. https://doi.org/10.1080/10941665.2016.1182038

Li, X. R., Lai, C., Harrill, R., Kline, S., \& Wang, L. (2011). When east meets west: An exploratory study on Chinese outbound tourists' travel expectations. Tourism management, 32(4), 741-749. https://doi.org/10.1016/j.tourman.2010.06.009

Lu, K., Chen, Y., \& Qu, Z. (2017, September). Research on synergistic governance of famous historical and cultural villages. In 2nd International Conference on Judicial, Administrative and Humanitarian Problems of State Structures and Economic Subjects (JAHP 2017). Atlantis Press. https://doi.org/10.2991/jahp-17.2017.10 
Li, C., \& Borbon, N. M. D.

Mutanga, C. N., Vengesayi, S., Chikuta, O., Muboko, N., \& Gandiwa, E. (2017). Travel motivation and tourist satisfaction with wildlife tourism experiences in Gonarezhou and Matusadona National Parks, Zimbabwe. Journal of Outdoor Recreation and Tourism, 20, 1-18. https://doi.org/10.1016/j.jort.2017.08.001

Sekiguchi, T., Hayashi, N., Sugino, H., \& Terada, Y. (2019). The effects of differences in individual characteristics and regional living environments on the motivation to immigrate to hometowns: A decision tree analysis. Applied Sciences, 9(13), 2748. https://doi.org/10.3390/app9132748

Timothy, D. J. (2011). Cultural heritage and tourism. Channel View Publication. https://doi.org/10.21832/9781845411787

Yin, P. (2012). Study of the influence of tourism transport cost on tourism destination spatial competition. Areal Research and Development, 31(6), 87-91.

Zhang, J., \& Liu, Y. (2021). Impact of scenic area environment and sports experience satisfaction on tourists' perception of environmental restoration. Journal of Zhejiang A\&F University, 38(1), 184-192. 